\title{
The impact of coping strategies of cancer caregivers on psychophysiological outcomes: an integrative review
}

This article was published in the following Dove Press journal:

Psychology Research and Behavior Management

\author{
Ricardo João Teixeira ${ }^{1-4}$ \\ Allison J Applebaum ${ }^{5}$ \\ Sangeeta Bhatia ${ }^{6}$ \\ Tânia Brandão ${ }^{7}$ \\ 'Department of Education and \\ Psychology, University of Aveiro, \\ Aveiro, Portugal; ${ }^{2}$ Clínica daOrdem, \\ Porto, Portugal; ${ }^{3}$ CESPU, Institute of \\ Research and Advanced Training in \\ Health Sciences and Technologies, \\ Gandra, Portugal; ${ }^{4}$ MamaHelp, Breast \\ Cancer Support Center, Porto. \\ Portugal; ${ }^{5}$ Memorial Sloan Kettering \\ Cancer Center, New York, NY, USA; \\ ${ }^{6}$ Department of Psychology, Gargi \\ College, University of Delhi, New \\ Delhi, India; ${ }^{7}$ Departamento de \\ Psicologia, Centro de Investigação em \\ Psicologia (CIP-UAL), Universidade \\ Autónoma de Lisboa Luís de Camões, \\ Lisboa, Portugal
}

\begin{abstract}
Purpose: A growing number of studies have explored the psychosocial burden experienced by cancer caregivers, but less attention has been given to the psychophysiological impact of caregiving and the impact of caregivers' coping strategies on this association. This paper reviews existing research on the processes underlying distress experienced by cancer caregivers, with a specific focus on the role of coping strategies on psychophysiological correlates of burden.

Methods: A broad literature search was conducted in health-related databases namely MEDLINE, Science Citations Index Expanded, Scopus, and PsycINFO, using relevant search terms. All types of studies published in English were considered for inclusion.

Results: We found that cancer caregiving was related to increased blood pressure, dysregulation of autonomic nervous system, hypothalamic-pituitary-axis dysregulation, immune changes, and poor health-related behaviors. We also found that problem-focused coping was associated with decreased caregiver burden, decreased depression, and better adjustment, while emotion-focused coping was related to higher levels of posttraumatic growth and psychological distress. The way coping impacts psychophysiological correlates of burden, however, remains unexplored.

Conclusion: A better understanding of the psychophysiological elements of caregiver burden is needed. We propose a model that attends specifically to factors that may impact psychophysiological correlates of burden among cancer caregivers. Based on the proposed model, psychosocial interventions that specifically target caregivers' coping and emotion regulation skills, family functioning, and self-care are endemic to the preservation of the health and wellbeing of this vulnerable population.
\end{abstract}

Keywords: cancer, caregiver, burden, coping, psychophysiology

\section{Background}

Throughout history, the provision of informal care by family members and friends has been a critical avenue for the protection of individuals with chronic health problems. ${ }^{1}$ Caregivers have always held significant socioeconomic value in society, one that will likely increase exponentially in the future as the number of individuals with chronic medical illnesses continues to rise. For example, the annual economic value of informal caregiving (i.e., providing care to a loved one with a chronic medical illness without being compensated financially to do so) in the USA was recently estimated at $\$ 375$ billion. $^{2}$

While the negative impact of caregiving has been widely documented, much less attention has been given to ways in which such negative outcomes may be avoided. ${ }^{3}$ The objective of this review was to examine the role of coping strategies on dimensions
Correspondence: Ricardo João Teixeir Department of Education and Psychology, University of Aveiro, Campus Universitário de Santiago, 3810-193

Aveiro, Portugal

Tel +35I 234370353

Email ricardojft@gmail.com 
of stress and negative health outcomes, with a specific focus on psychophysiological correlates of burden among cancer caregivers. Since psychological adjustment to cancer is a dynamic process that depends in part on the meaning attributed to the illness and coping strategies employed to face emotional exhaustion and perceived lack of control, a greater understanding of caregivers' coping strategies will directly inform the development of empirically supported interventions that attend to the unique psychological symptoms of burden experienced by cancer caregivers. ${ }^{3,4}$

\section{Caregiver burden}

A large body of literature suggests that providing care to a chronically ill loved one has the potential to cause caregiver burden. Specifically, cancer has the potential to significantly and negatively impact patients and their informal caregivers, for whom the disease trajectory represents a significant source of distress and burden. ${ }^{5}$ According to the Oncology Nursing Society, ${ }^{6}$ caregiver burden encompasses the difficulties of the caregiver role and the associated alterations in caregivers' emotional and physical health that can occur when care demands exceed resources. Caregivers experience varying challenges during different phases of the cancer trajectory that can significantly impact their functioning and quality of life. Indeed, close to one-half of caregivers of patients with advanced cancer have some symptoms of distress (e.g., depression, anxiety, insomnia, and decreased quality of life). ${ }^{7}$ Moreover, family members significantly involved in the patient's care, and who report a significant impact of caregiving on their daily activities, often report fatigue and burden associated with the patient's cognitive and physical dysfunction. ${ }^{8,9}$ Additionally, in families of patients at end of life, caregivers face the dual challenge of providing care and beginning to process anticipatory grief. These concerns are well recognized by health organizations that consider the patient and family as a unit of care, and offer support during the disease trajectory, from diagnosis to bereavement. ${ }^{10-12}$

\section{Emotional burden}

While rates of psychopathology are high among patients with cancer - higher than rates in the general population - new data suggest that the rates are even higher among their caregivers. For example, several reviews and meta-analyses have demonstrated a higher prevalence of psychiatric disorders, especially anxiety and depressive disorders, in caregivers when compared with individuals in the general population. ${ }^{13-17}$ Depression, in particular, has emerged as a primary focus of research. A literature review found that an estimated
$20 \%-73 \%$ of cancer caregivers experience depressive symptomatology, rates that are higher than those in the general population. ${ }^{18}$ Importantly, depression has been found to be associated with specific factors, including caregivers demographic characteristics (i.e., younger age, female gender, and spousal relationship with care recipient), negative appraisals of caregiving demands, and inadequate support received by the cancer caregiver. ${ }^{5,19,20}$ Moreover, the responsibility to fulfill roles in addition to cancer care, such as employment or childcare, may lead to greater emotional or psychological distress among caregivers. ${ }^{21}$ Lack of time, financial burden, and reduced income are also apparent among family members providing care to patients with cancer. ${ }^{22-24}$

\section{Physical burden}

While emotional aspects of caregiver burden have been thoroughly evaluated and documented, considerably less research has explored physical burden and psychophysiological correlates of such burden among caregivers. Caregivers are at risk of a range of physical health complications as a result of their role. ${ }^{25-27}$ These include sleep difficulties, ${ }^{28-30}$ fatigue, ${ }^{8,31}$ cardiovascular disease, ${ }^{32,33}$ poor immune functioning, ${ }^{34,35}$ and increased mortality. ${ }^{36,37}$ For example, Schulz and Beach ${ }^{36}$ found that caregivers who reported burden had a $63 \%$ increased risk of mortality when compared with noncaregivers. In addition, these caregivers were much less likely to have time to rest when sick, time to exercise, or to secure adequate rest to allow for optimal caregiving capacity. Studies have also reported poor health-related behaviors, such as increased alcohol and tobacco use. ${ }^{38,39}$ In fact, some studies indicate that caregivers are less likely to undertake preventive health behaviors and generally exhibit decreased health care service utilization. ${ }^{40}$

\section{Positive outcomes of caregiving}

Although a majority of studies have highlighted the negative outcomes of caregiving, some positive outcomes of caregiving have also been reported. Recent systematic reviews have identified positive aspects in informal caregiving. These include improved mood, better relationship satisfaction, personal growth, competence and mastery, better subjective well-being, and even better cognitive functioning and lower mortality. ${ }^{41,42}$ Using a diary methodology, Cheng et $\mathrm{al}^{43}$ found that Alzheimer caregivers were capable of identifying several positive gains within this process, such as a sense of purpose, feelings of gratification, increased tolerance, or even cultivation of positive meanings. In the specific context of cancer, caregiving was also associated with positive experiences. In two recent systematic reviews, caregivers reported feelings 
of being rewarded, personal growth, and finding meaning, personal satisfaction and discovery of personal strength, and improved their relationship, not only with the care-receiver, but also within other relationships. ${ }^{44,45}$

\section{This review}

The purpose of this review was to provide an extensive overview of the state of literature in relation to the psychophysiological consequences of caregiving and the role of coping strategies on this association. To that end, we first review the status of the relationship between caregiving and psychophysiological stress responses, and the association between coping and psychophysiological correlates of burden. Based on our findings and on previous models, we propose a model to guide research within this field. We conclude by outlining potential lines of inquiry for future research.

\section{Methodology}

A broad literature search on the processes underlying distress experienced by cancer caregivers, with a specific focus on the impact of coping strategies on psychophysiological correlates of burden was conducted using several databases, namely MEDLINE, Science Citation Index Expanded, Scopus, and PsycINFO. To this end, keywords such as "cancer", “oncology", “caregiver", "caregiving”, "carer", “coping”, or "coping strategies", "burden", "physiology", "distress" were used. All types of studies (e.g., quantitative, qualitative), published in English, assessing 1) psychophysiological stress responses in the context of caregiving and 2) the association between coping strategies and psychophysiological correlates of burden in samples of cancer caregivers were included.

\section{Results}

A total of 30 articles were identified. From these, four articles exploring the link between caregiving and psychophysiological stress responses and five articles exploring the association between coping strategies and psychophysiological correlates were included in this review. Study characteristics and main results are presented in Tables 1 and 2. Given the lack of studies found, results from included studies were also related to studies from other caregiving contexts and from the broad psychophysiological literature to better understand the results obtained in the context of cancer caregiving.

Table I Study characteristics and main results of included studies for associations between caregiving and psychophysiological stress responses $(\mathrm{N}=4)$

\begin{tabular}{|c|c|c|}
\hline Study references & Study design & Results \\
\hline Weitzner et al, ${ }^{47} 2000$ & $\begin{array}{l}\text { Review - caregiving among older cancer } \\
\text { patients }\end{array}$ & $\begin{array}{l}\text { Caregiving was associated with lowered immune system functioning, increase } \\
\text { in blood pressure, and altered lipid profiles. }\end{array}$ \\
\hline Lucini et al, ${ }^{48} 2008$ & $\begin{array}{l}\text { Observational study with } 58 \text { cancer } \\
\text { caregivers (vs. } 60 \text { controls) }\end{array}$ & $\begin{array}{l}\text { Caregivers showed an autonomic imbalance, suggestive of sympathetic } \\
\text { predominance at rest and of a reduction of vagal cardiac regulation. }\end{array}$ \\
\hline $\begin{array}{l}\text { Teixeira and Pereira, } \\
2014\end{array}$ & $\begin{array}{l}\text { Cross-sectional study with } 78 \text { cancer } \\
\text { caregivers (vs. } 78 \text { controls) }\end{array}$ & $\begin{array}{l}\text { Cancer caregivers showed higher cardiovascular (heart rate) and } \\
\text { electrodermal reactivity (skin conductance) while visualizing standardized } \\
\text { pictures with different emotional valences. }\end{array}$ \\
\hline $\begin{array}{l}\text { Luecken and Lemery, }{ }^{55} \\
2004\end{array}$ & $\begin{array}{l}\text { Review - early caregiving and pathways to } \\
\text { dysregulated physiological stress responses }\end{array}$ & $\begin{array}{l}\text { Different genetic, psychosocial, and cognitive-affective pathways to } \\
\text { dysregulated physiological stress responses among caregivers were found. }\end{array}$ \\
\hline
\end{tabular}

Table 2 Study characteristics and main results of included studies for associations between coping strategies and psychophysiological correlates $(\mathrm{N}=5)$

\begin{tabular}{|c|c|c|}
\hline Study references & Study design & Results \\
\hline $\begin{array}{l}\text { Patrick and Hayden, }{ }^{60} \\
1999\end{array}$ & $\begin{array}{l}\text { Cross-sectional study with } 596 \text { women with an } \\
\text { adult child with a chronic disability }\end{array}$ & Coping strategies were associated with well-being. \\
\hline $\begin{array}{l}\text { Elliott and } \\
\text { Shewchuk, }{ }^{61} 2003\end{array}$ & $\begin{array}{l}\text { Cross-sectional study with } 60 \text { caregivers of } \\
\text { patients with several physical disabilities }\end{array}$ & $\begin{array}{l}\text { Problem-focused coping was associated with depression, mental health, } \\
\text { social functioning, and vitality. }\end{array}$ \\
\hline $\begin{array}{l}\text { Fuemmeler et al, }{ }^{62} \\
2005\end{array}$ & $\begin{array}{l}\text { Cross-sectional study with } 47 \text { parents of } \\
\text { childhood cancer survivors (vs. } 3 \text { I parents of } \\
\text { children with type I diabetes mellitus) }\end{array}$ & $\begin{array}{l}\text { Lower levels of emotion-focused coping were associated with increased } \\
\text { frequency of both posttraumatic stress symptoms and general } \\
\text { psychological distress. }\end{array}$ \\
\hline $\begin{array}{l}\text { Hoekstra-Weebers } \\
\text { et al, }{ }^{63} 2000\end{array}$ & $\begin{array}{l}\text { Longitudinal study with parents of pediatric } \\
\text { cancer patients }\end{array}$ & $\begin{array}{l}\text { Coping was associated with levels of distress and was a buffer for } \\
\text { depression. }\end{array}$ \\
\hline $\begin{array}{l}\text { Schumacher et al, }{ }^{64} \\
1993\end{array}$ & $\begin{array}{l}\text { Longitudinal study with } 75 \text { caregivers of persons } \\
\text { receiving chemotherapy }\end{array}$ & $\begin{array}{l}\text { Coping strategies were associated with both strain and depression. } \\
\text { Further analysis showed that coping mediated the relationship between } \\
\text { strain and depression. }\end{array}$ \\
\hline
\end{tabular}




\section{Caregiving and psychophysiological stress responses}

Although certain physiological responses (e.g., increase in cardiovascular function and a release of adrenal catecholamines) are anticipated and considered adaptive during the initial reaction to an acute stressor ${ }^{46}$ such as the diagnosis of cancer in oneself or a loved one, ${ }^{39}$ a period of chronic stress - such as that experienced during the cancer caregiving trajectory - can lead to changes in cardiovascular and immune functioning that are no longer adaptive, but instead have the potential to compromise the physical well-being of the caregiver. In their review, Weitzner et al ${ }^{47}$ found that when faced with demanding care situations, cancer caregivers present a lowered immune system functioning, an increase in blood pressure, and altered lipid profiles, leading to a state of enhanced psychological morbidity and burden. In another study, Lucini et $\mathrm{a}^{18}$ evaluated the effects of caregiving as a risk factor for poor health in caregivers of cancer patients and noncaregivers. The study included the investigation of psychological and physiological (autonomic nervous system) measures. The results indicated that cancer caregivers showed dysregulation of the autonomic nervous system, which was attributed to stressors associated with caregiving. The experience of stress led to an activation of the hypothalamic-pituitary-axis (HPA) and immune changes, as well as behavioral alterations such as adoption of poor health-related behaviors. The results revealed that since cancer caregivers had higher levels of stress, and an obvious autonomic imbalance, there was a reduction in cardiac vagal regulation, which significantly compromised their health status. This result, as well as others reported by Teixeira and Pereira ${ }^{49}$ suggests the need to carry out preventive strategies to improve the autonomic profile of cancer caregivers. For example, decreased immune functioning may occur as a result of diminished cytokine production (considered mediators and regulators of innate immunity), eventually compromising the body in relation to the ability to cope with a disease..$^{50,51}$

Recent research has begun to identify mechanisms through which the caregiving experience impacts health outcomes. Previous reviews ${ }^{52}$ have identified several potential mechanisms, including the ability to regulate psychophysiological responses to environmental challenges. For example, psychophysiological stress responses prepare the body to survive physical threats by mobilizing stored energy, increasing cardiac output, and suppressing nonessential digestive, immune, and reproductive functions. ${ }^{46}$ At a psychophysiological level, research also suggests that the combination of prolonged stress and physical demands of caregiving can compromise the physiological functioning of caregivers and increase the risk of health problems ${ }^{53,54} \mathrm{As}$ Luecken and Lemery's study ${ }^{55}$ suggests, caregiving may be associated, in the long term, with dysregulated physiological stress responses and, ultimately, disease outcomes. Beyond the genetic and the psychosocial pathways, Davies and Cummings reflect on a cognitive-affective pathway, suggesting that caregiving experiences influence the development of cognitive and emotional self-regulatory abilities and threat appraisals, which can then alter subsequent responses to stress. In fact, affective self-regulation has been linked with improved coping with daily stressors, ${ }^{56}$ lower levels of aggression and hostility, ${ }^{57}$ and improved health-related behaviors. ${ }^{58}$ Therefore, the manner in which individuals make sense of situations has the potential to impact both behavioral and physiological responses.

\section{Coping and psychophysiological correlates of burden}

Similar to the dearth of studies that systematically examine the impact of specific coping strategies on psychological outcomes, very little attention has been given to the impact of caregivers' coping strategies on psychophysiological correlates of burden. ${ }^{59}$ For example, problem-focused coping has been associated with decreased caregiver burden, ${ }^{60}$ while problem-solving ability of the caregiver of a physically disabled family member has been found to predict improved adjustment and decreased depression. ${ }^{61}$ Additionally, emotion-focused coping has been associated with higher levels of posttraumatic stress disorder symptoms and general psychological distress in parents of children with cancer and diabetes. ${ }^{62}$ When coping styles were investigated longitudinally among cancer caregivers, problem-focused coping was most effective at the time of diagnosis, a point which requires learning about the illness and exploring treatment options. ${ }^{63}$ The same study also revealed that coping styles shifted as treatment progressed, and that previous coping styles did not necessarily impact later level of distress. There is also evidence that coping styles can act as a buffer for depression in cancer caregivers. For example, Schumacher et $\mathrm{a}^{64}$ found that caregivers' perceptions of the efficacy of their coping strategies mediated the relationship between strain and depression. However, when compared with other dimensions of the cancer caregiving context such as stress or depression, coping has remained relatively unexplored. 


\section{Discussion}

Given the vast literature documenting caregiver burden and the multiply determined nature of such burden, the field of psychooncology is increasingly turning its attention to coping and how mental health professionals may help cancer caregivers to cope with the many demands they face. Indeed, the growing recognition of the critical role that informal caregivers play in our health care systems has been met with equal attention by researchers and government agencies alike on ways in which the health and well-being of cancer caregivers can be maintained.

This integrative review provides evidence of the lack of studies exploring the association between caregiving and psychophysiological outcomes and examining the role of coping on these associations. Yet, some evidence was gathered regarding the impact of caregiving on blood pressure, HPA function, immune function, and health-related behaviors. Moreover, coping strategies used by cancer caregivers seem to influence their psychosocial adaptation and, consequently, may affect their psychophysiological outcomes.

To better understand the experience of cancer caregivers, several models have been proposed (Table 3) ${ }^{65-67}$

In light of the literature reviewed here and the fact that the previous models ${ }^{22,40,69-71}$ do not specifically attend to psychophysiological indicators of burden, we propose an explanatory model that accounts for this important element of the caregiving experience (Figure 1). Contextual factors (e.g., age, gender, family variables, and emotional development), cancer-related events of the caregiver (previous caregiving experiences and other stressors), and disease characteristics and treatments (i.e., nature of the cancer and treatments) may impact the way caregivers make sense of a situation in terms of demands, stressors, and goals (i.e., cognitive reappraisal) as well as the way they think about the presence or absence of internal and external resources to meet these demands, stressors, and goals. This cognitive appraisal informs the experience of burden, as indicated via psychophysiological mechanisms. Specifically, such burden may manifest as an activation of the HPA axis and the sympathetic adrenomedullary system (i.e., reduction in cardiac vagal regulation and increased blood pressure), or neuroendocrine and immune changes, such as diminished cytokine production and elevated release of cortisol. These psychophysiological responses, however, can be modulated by caregivers' coping strategies and specific psychosocial variables. Some authors ${ }^{57,72,73}$ have proposed that effectiveness of coping strategies and, specifically, cognitive appraisals, are linked to psychophysiological reactivity to stress, with negative appraisals being associated with increased cardiovascular reactivity.

For this reason, we propose that the extent of psychophysiological dysregulation experienced by caregivers is impacted by the use of targeted coping strategies (problem-, emotion-, and meaning-focused) previously described, as well as caregivers' engagement in optimal emotion regulation strategies (vs. worry, rumination) and self-care (vs. poor health-related behaviors), the existence of family function (vs. dysfunction), and capacity to maintain a present focus (vs. becoming overwhelmed with the perception of the chronicity of the caregiving trajectory). These factors together will impact caregivers' appraisals of the situation (in terms of perceived harm and threat and capacity to overcome these limitations) and hence, the psychophysiological outcomes experienced.

\section{Future directions}

It is clear that psychosocial interventions that target the unique needs of cancer caregivers are needed. In particular, this review highlights the potential benefits of interventions that attend not only to symptoms of burden, but also the mechanisms underlying such symptom profiles. Importantly, our proposed model suggests multiple avenues for

Table 3 Models for understanding the experience of cancer caregivers

\begin{tabular}{|c|c|c|}
\hline & $\begin{array}{l}\text { The caregiver stress model } \\
\left(\text { Pearlin et } \mathrm{al}^{40}\right)\end{array}$ & $\begin{array}{l}\text { The theory of stress and coping } \\
\text { (Lazarus and Folkman }{ }^{68} \text { ) }\end{array}$ \\
\hline Background and the context & $\begin{array}{l}\text { SES, caregiving history, family and network composition, } \\
\text { program availability }\end{array}$ & Personal and situational factors \\
\hline The stressors & $\begin{array}{l}\text { Primary stressors: } \\
\text { I) Objective indicators - cognitive status, problematic } \\
\text { behaviors, IADL, dependences } \\
\text { 2) Subjective indicators - overload, relational deprivation }\end{array}$ & $\begin{array}{l}\text { Acute or chronic stressors and their appraisal } \\
\text { (primary and secondary) }\end{array}$ \\
\hline The mediators & Coping, social support & $\begin{array}{l}\text { Coping (emotional-focused, problem-solving, } \\
\text { meaning-focused) }\end{array}$ \\
\hline The outcomes & $\begin{array}{l}\text { Depression, anxiety, irascibility, cognitive disturbance, } \\
\text { physical health, yielding of role }\end{array}$ & Health and well-being \\
\hline
\end{tabular}

Abbreviations: IADL, instrumental activities of daily living; SES, socioeconomic status. 


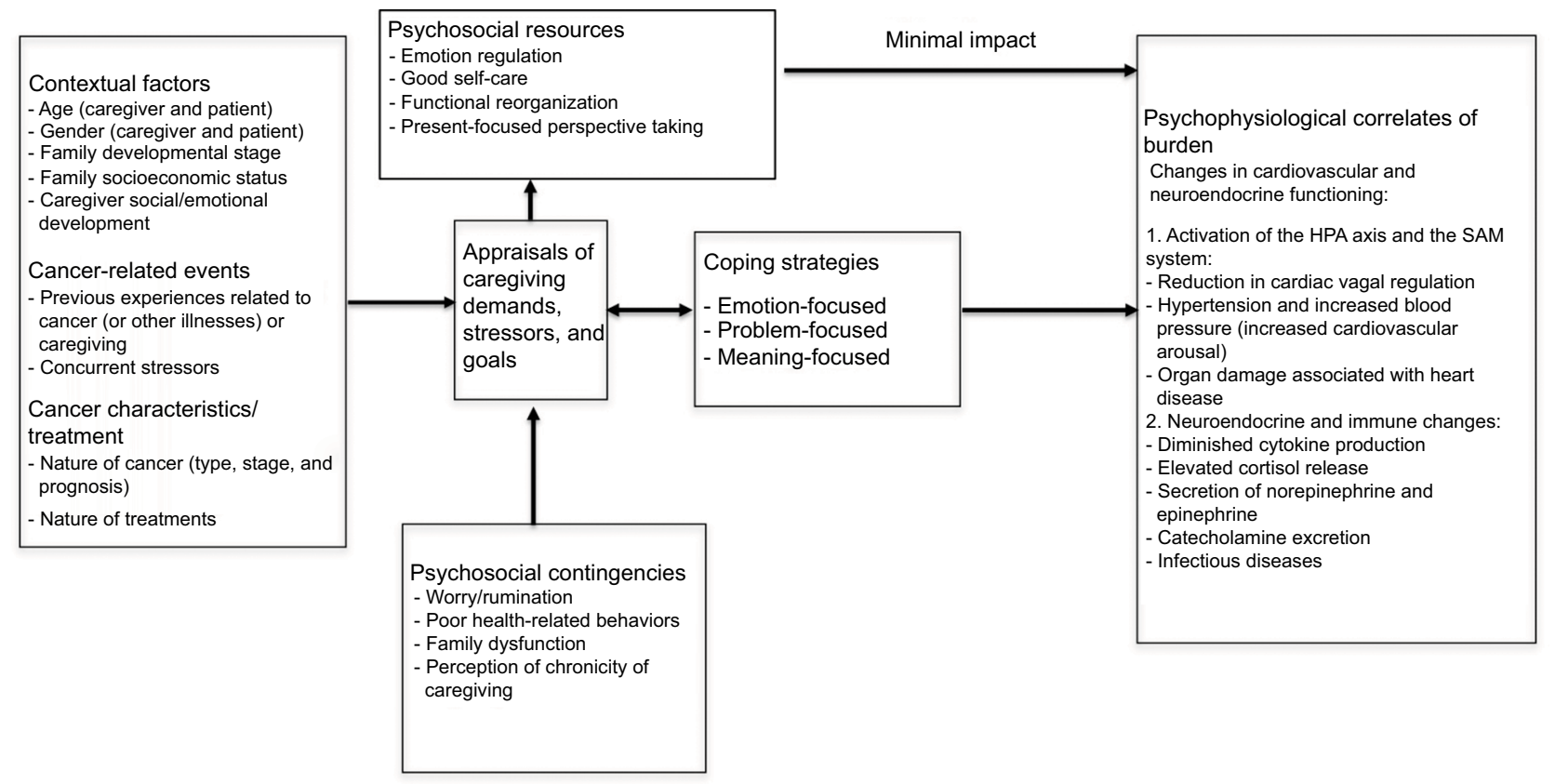

Figure I A proposed model of the impact of coping strategies of cancer caregivers on psychophysiological indicators of burden. Abbreviations: HPA, hypothalamic-pituitary-axis; SAM, sympathetic adrenomedullary.

intervention, including the facilitation of improved coping strategies, improved emotion regulation skills, self-care, and family functioning.

The present review suggests that, since coping strategies can be learned, interventions that target and provide psychoeducation about coping and adaptive strategies can be useful in preventing and/or decreasing burden, both as measured via subjective rating scales and physiological measurement tools. Drawing on the work of Lazarus and Folkman ${ }^{68}$ and Folkman, ${ }^{74}$ interventions that help caregivers to identify elements of the current caregiving-related challenges that are controllable or uncontrollable, and that teach problem-focused, emotion-focused, and meaning-focused skills have the potential to promote resilience and buffer distress and burden. Indeed, two systematic reviews of psychosocial interventions for cancer caregivers ${ }^{75,76}$ highlighted the significant benefits of problem-solving and skills building interventions in assisting caregivers with carrying out their responsibilities and cultivating a sense of mastery and control. These reviews - in addition to the earlier reviews of Northouse et $\mathrm{al}^{77,78}$ - also emphasized a dearth of interventions that target specific domains of caregiver needs, such as existential distress and insomnia.

Interventions that attend to caregivers' emotion regulation skills and ability to manage negative emotions in a healthful way are also critical in light of the expected emergence of negative emotions across the caregiving trajectory. One such intervention, Emotion Regulation Therapy (ERT), originally developed by Mennin and Fresco ${ }^{79}$ to address worry and rumination in individuals in the general population is currently being adapted to address the processes that underlie anxiety and mood symptoms among cancer caregivers (Emotion Regulation Therapy for Cancer Caregivers; ERT-C). Preliminary analyses have demonstrated strong effects of the ERT-C on rumination, worry, intolerance of uncertainty, and anxious and depressive symptomatology among cancer caregivers. ${ }^{80,81}$

Importantly, longitudinal studies that examine the experience of caregivers across the caregiving trajectory, from diagnosis to bereavement, and through survivorship, are needed to provide a clearer understanding of the progress of psychological well-being and coping processes of caregivers. Such studies have the potential to highlight critical points, such as diagnosis or relapse, at which distress among caregivers is likely to increase, and in so doing, clearly define critical time points for optimal psychotherapeutic intervention. Studies that examine the unique needs of caregivers of patients with specific types of cancer (e.g., brain tumors) or undergoing specific treatment regimens (e.g., hematopoietic stem-cell transplantation) are also needed so that interventions may target the unique burden experienced by these groups. Work is already underway ${ }^{82}$ to develop such interventions for hematopoietic-stem-cell-transplant caregivers. Additionally, studies that examine the impact of life and developmental 
stage on the caregiving experience will allow for a greater understanding of the context of burden among caregivers. ${ }^{83,84}$ This, in turn, may highlight variable approaches to coping that are particularly consonant with certain stages in life.

Most critically, systematic study of the psychophysiological correlates of burden is needed in order to understand the broad impact of caregiving on the caregiver. As cancer caregivers themselves represent a population at risk of cancer and other chronic medical illnesses, such attention is critical in order to mitigate the impact of caregiving stress on this vulnerable population.

\section{Disclosure}

The authors report no conflicts of interest in this work.

\section{References}

1. Lebel S, Trinkaus E, Faure M, et al. Comparative morphology and paleobiology of Middle Pleistocene human remains from the Bau de l'AubesierVaucluse, France. Proc Natl Acad Sci USA 2001;98(20):11097-11102.

2. AARP. Valuing the invaluable: The economic value of family caregiving. Available from: http://www.aarp.org/relationships/caregiving/info-112008/i13_caregiving.htmlExternal2008. Accessed March 30, 2014.

3. FitzellI A, Pakenham, KI. Application of a stress and coping model to positive and negative adjustment outcomes in colorectal cancer caregiving. Psychooncology. 2010;19(11):1171-1178.

4. Kershaw T, Northouse L, Kritpracha C, Schafenacker A, Mood D. Coping strategies and quality of life in women with advanced breast cancer and their family caregivers. Psych Health. 2004;19(2):139-155.

5. Haley WE. The costs of family caregiving: implications for geriatric oncology. Crit Rev Oncol Hematol. 2003;48(2):151-158.

6. Oncology Nursing Society. Caregiver Strain and Burden. Available from: http://www.ons.org/practice-resources/pep/caregiver-strain-andburden2014. Accessed March 30, 2014.

7. Östlund W, Wennman-Larsen A, Persson C, Gustavsson P, Wengström Y. Mental health in significant others of patients dying from lung cancer. Psychooncology. 2010;19(1):29-37.

8. Jensen S, Given BA. Fatigue affecting family caregivers of cancer patients. Cancer Nurs.1991;14(4):181-187.

9. Winningham ML, Barton-Burke M. Fatigue in Cancer. London: Jones and Bartlett Publishers; 2000.

10. Biondi M, Picardi A. Clinical and biological aspects of bereavement and loss induced depression: a reappraisal. Psychother Psychosom. 1996;65(5):229-245.

11. Chentsova-Dutton Y, Shucter S, Hutchin S, et al. Depression and grief reactions in hospice caregivers: from pre-death to 1 year afterwards. $J$ Affect Disord. 2002;69(1-3):53-60.

12. Schulz R, Beach SR, Lind B, et al. Involvement in caregiving and adjustment to death of a spouse. Findings from the Caregiver Health Effects Study. JAMA. 2001;285(24):3123-3129.

13. Chentsova-Dutton Y, Shuchter S, Hutchin S, Strause L, Burns K, Zisook S. The psychological and physical health of hospice caregivers. Ann Clin Psychiatry. 2000;12(1):19-27.

14. Cochrane JJ, Goering PN, Rogers JM. The mental health of informal caregivers in Ontario: an epidemiological survey. Am J Public Health.1997;87(12):2002-2007.

15. Karlin NJ, Retzlaff PD. Psychopathology in caregivers of the chronically ill: personality and clinical syndromes. Hosp J. 1995;10(3): 55-61.

16. Pruchno RA, Potashnik SL. Caregiving spouses. Physical and mental health in perspective. J Am Geriatr Soc. 1989;37(8):697-705.
17. Schulz R, O’Brien AT, Bookwala J, Fleissner K. Psychiatric and physical morbidity effects of dementia caregiving: prevalence, correlates, and causes. Gerontologist. 1995;35(6):771-791.

18. Swore-Fletcher BA, Dodd MJ, Schumacher KL, Miaskowski C. Symptom experience of family caregivers of patients with cancer. Oncol Nurs Forum. 2008;35(2):E23-E44.

19. Nijboer C, Tempelaar R, Sanderman R, Triemstra M, Spruijt RJ, van den Bos, GA. Cancer and caregiving: the impact on the caregiver's health. Psychooncology.1998;7(1):3-13.

20. Raveis VH, Karus DG, Siegel K. Correlates of depressive symptomatology among adult daughter caregivers of a parent with cancer. Cancer.1998;83(8):1652-1663.

21. Gaston-Johansson F, Lachica EM, Fall-Dickson JM, Kennedy MJ. Psychological distress, fatigue, burden of care, and quality of life in primary caregivers of patients with breast cancer undergoing autologous bone marrow transplantation. Oncol Nurs Forum. 2004;31(6):1161-1169.

22. Gaugler JE, Linder J, Given CW, Kataria R, Tucker G, Regine WF. The proliferation of primary cancer caregiving stress to secondary stress. Cancer Nurs. 2008;31(2):116-123.

23. Hanratty B, Holland P, Jacoby A, Whitehead M. Financial stress and strain associated with terminal cancer-a review of the evidence. Palliat Med. 2007;21(7):595-607.

24. Brazil K, Bainbridge D, Rodriguez C. The stress process in palliative cancer care: a qualitative study on informal caregiving and its implication for the delivery of care. Am J Hosp Palliat Care. 2010;27(2): $111-116$.

25. Burton LC, Newsom JT, Schulz R, Hirsch CH, German PS. Preventive health behaviors among spousal caregivers. Prev Med. 1997;26(2): $162-169$.

26. Given CW, Given B, Stommel M, Collins C, King S, Franklin S. The caregiver reaction assessment (CRA) for caregivers to persons with chronic physical and mental impairments. Res Nurs Health.1992;15(4): 271-283.

27. Given B, Wyatt G, Given C, et al. Burden and depression among caregivers of patients with cancer at the end of life. Oncol Nurs Forum. 2004;31(6): $1105-1117$.

28. Carter PA. Family caregivers' sleep loss and depression over time. Cancer Nurs. 2003;26(4):253-259.

29. Cho MH, Dodd MJ, Lee KA, Padilla G, Slaughter R. Self-reported sleep quality in family caregivers of gastric cancer patients who are receiving chemotherapy in Korea. J Cancer Educ. 2006;21(Suppl1):S37-S41.

30. Hearson B, McClement S. Sleep disturbance in family caregivers of patients with advanced cancer. Int J Palliat Nurs. 2007;13(10):495-501.

31. Teel CS, Press AN. Fatigue among elders in caregiving and noncaregiving roles. West J Nurs Res. 1999;21(4):498-514.

32. Lee S, Colditz GA. Berkman LF, Kawachi I. Caregiving and risk of coronary heart disease in U.S. women: a prospective study. Am J Prev Med. 2003;24(2):113-119.

33. von Känel R, Mausbach BT, Patterson TL, et al. Increased Framingham coronary heart disease risk score in dementia caregivers relative to non-caregiving controls. Gerontology. 2008;54(3):131-137.

34. Kiecolt-Glaser JK, Fisher LD, Ogrocki P, Stout JC, Speicher CE, Glaser, R. Marital quality, marital disruption, and immune function. Psychosom Med. 1987;49(1):13-34.

35. Rohleder N, Marin TJ, Ma R, Miller GE. Biologic cost of caring for a cancer patient: dysregulation of pro- and anti-inflammatory signaling pathways. J Clin Oncol. 2009;27(18):2909-2915.

36. Schulz R, Beach SR. Caregiving as a risk factor for mortality: the Caregiver Health Effects Study. JAMA. 1999;282(23):2215-2219.

37. Christakis NA, Allison PD. Mortality after the hospitalization of a spouse. N Engl J Med. 2006;354(7):719-730.

38. Riess-Sherwood P, Given BA, Given CW. Who cares for the caregiver: strategies to provide support. Home Health Care Manag Pract. 2002;14(2):110-121.

39. Sherwood PR, Given BA, Donovan H, et al. Guiding research in family care: a new approach to oncology caregiving. Psychooncology. 2008;17(10):986-996. 
40. Pearlin LI, Mullan JT, Semple SJ, Skaff, MM. Caregiving and the stress process: an overview of concepts and their measures. Gerontologist. 1990;30(5):583-594.

41. Brown RM, Brown SL. Informal caregiving: a reappraisal of effects on caregivers. Soc Issues Policy Rev. 2014;8(1):74-102.

42. Lloyd J, Patterson T, Muers J. The positive aspects of caregiving in dementia: a critical review of the qualitative literature. Dementia. 2016;15(6): 1534-1561.

43. Cheng ST, Mak EP, Lau RW, Ng NS, Lam LC. Voices of Alzheimer caregivers on positive aspects of caregiving. Gerontologist. 2015;56(3): 451-460.

44. Li Q, Loke AY. A systematic review of spousal couple-based intervention studies for couples coping with cancer: direction for the development of interventions. Psychooncology. 2014;23(7):731-739.

45. Stenberg U, Ekstedt M, Olsson M, Ruland CM. Living close to a person with cancer: a review of the international literature and implications for social work practice. J Gerontol Soc Work. 2014;57(6-7):531-555.

46. Jansen AS, Nguyen XV, Karpitskiy V, Mettenleiter TC, Loewy AD. Central command neurons of the sympathetic nervous system: basis of the fight-or-flight response. Science. 1995;270(5236):644-646.

47. Weitzner MA, Haley WE, Chen $\mathrm{H}$. The family caregiver of the older cancer patient. Hematol Oncol Clin North Am. 2000;14(1):269-281.

48. Lucini D, Cannone V, Malacarne M, et al. Evidence of autonomic dysregulation in otherwise healthy cancer caregivers: a possible link with health hazard. Eur J Cancer. 2008;44(16):2437-2443.

49. Teixeira RJ, Pereira MG. Psychological morbidity and autonomic reactivity to emotional stimulus in parental cancer: a study with adult children caregivers. Eur J Cancer Care. 2014;23(1):129-139.

50. DeRijk RH, Schaaf M, de Kloet, ER. Glucocorticoid receptor variants: clinical implications. J Steroid Biochem Mol Biol. 2002;81(2):103-122.

51. Padgett DA, Glaser R. How stress influences the immune response. Trends Immunol. 2003;24(8):444-448.

52. Repetti RL, Taylor SE, Seeman TE. Risky families: family social environments and the mental and physical health of offspring. Psychol Bull. 2002;128(2):330-366.

53. Kiecolt-Glaser JK, Glaser R, Gravenstein S, Malarkey WB, Sheridan J. Chronic stress alters the immune response to influenza virus vaccine in older adults. Proc Natl Acad Sci USA. 1996;93(7):3043-3047.

54. Schulz R, Newsom J, Mittelmark M, Burton L, Hirsch C, Jackson S. Health effects of caregiving: the caregiver health effects study: an ancillary study of the Cardiovascular Health Study. Ann Behav Med. 1997;19(2):110-116.

55. Luecken LJ, Lemery KS. Early caregiving and physiological stress responses. Clin Psychol Rev. 2004;24(2):171-191.

56. Davies PT, Cummings EM. Marital conflict and child adjustment: an emotional security hypothesis. Psychol Bull. 1994;116(3):387-411.

57. Taylor SE, Repetti RL, Seeman T. Health psychology: what is an unhealthy environment and how does it get under the skin? Annu Rev Psychol. 1997;48:411-447.

58. McCubbin HI, Needle RH, Wilson M. Adolescent health risk behaviors: family stress and adolescent coping as critical factors. Fam Relat. $1985 ; 34: 51-62$

59. Bucher J, Zabora J. Building problem-solving skills through COPE education of family caregivers. In: Holland JC, Breitbart WS, Jacobsen PB, Lederberg MS, Loscalzo MJ, McCorkle R, editors. Psychooncology. 2nd ed. London, UK: Oxford University Press; 2010:469-472.

60. Patrick JH, Hayden JM. Neuroticism, coping strategies, and negative well-being among caregivers. Psychol Aging. 1999;14(2):273-283.

61. Elliott TR, Shewchuk RM. Social problem-solving abilities and distress among family members assuming a caregiving role. Br J Health Psychol. $2003 ; 8(\mathrm{Pt} 2): 149-163$.

62. Fuemmeler B, Mullins LL, Van Pelt JC, Carpentier MY, Parkhurst J. Posttraumatic stress symptoms and distress among parents of children with cancer. Children's Health Care. 2005;34(4):289-303.

63. Hoekstra-Weebers J, Jaspers J, Klip EC, Kamps WA. Factors contributing to the psychological adjustment of parents of paediatric cancer patients. In: Baider L, Cooper CL, De-Nour AK, editors. Cancer and the Family. England: John Wiley \& Sons; 2000:257-272.
64. Schumacher KL, Dodd MJ, Paul SM. The stress process in family caregivers of persons receiving chemotherapy. Res Nurs Health. 1993;16(6):395-404.

65. Sales E, Schulz R, Biegel D. Predictors of strain in families of cancer patients: a review of the literature. J Psychosoc Oncol. 1992;10(2):1-26.

66. Lewis FM. The impact of breast cancer on the family: lessons learned from the children and adolescents. In: Baider L, Cooper CL, De-Nour AK, editors. Cancer and the Family. Chichester: John Wiley \& Sons; 1996:271-287.

67. Brown MA, Stetz K. The labor of caregiving: a theoretical model of caregiving during potentially fatal illness. Qual Health Res. 1999;9(2):182-197.

68. Lazarus RS, Folkman, S. Psychological Stress and the Coping Process. New York: Springer; 1984.

69. Maes S, Leventhal H, De Ridder DTD. Coping with chronic dieseases. In: Ziender M, Endler NS, editors. Handbook of Coping: Theory, Research, Applications. New York: John Wiley \& Sons, Inc.; 1996:221-245.

70. Schumacher KL, Beidler SM, Beeber AS, Gambino P. A transactional model of cancer family caregiving skill. ANS Adv Nurs Sci. 2006;29(3):271-286.

71. Gaugler JE, Linder J, Given CW, Kataria R, Tucker G, Regine WF. Family cancer caregiving and negative outcomes: the direct and mediational effects of psychosocial resources. J Fam Nurs. 2009;15(4): 417-444.

72. Chen E, Matthews KA. Cognitive appraisal biases: an approach to understanding the relation between socioeconomic status and cardiovascular reactivity in children. Ann Behav Med. 2001;23(2): 101-111.

73. Flory JD, Matthews KA, Owens JF. A social information processing approach to dispositional hostility: relationships with negative mood and blood pressure elevations at work. J Soc Clin Psychol. 1998;17(4):491-504.

74. Folkman S. Personal control and stress and coping processes: a theoretical analysis. J Pers Soc Psychol. 1984;46(4):839-852.

75. Applebaum JA, Breitbart W. Care for the cancer caregiver: a systematic review. Palliat Support Care. 2013;11(3):231-252.

76. Waldron EA, Janke EA, Bechtel CF, Ramirez M, Cohen A. A systematic review of psychosocial interventions to improve cancer caregiver quality of life. Psychooncology. 2013;22(6):1200-1207.

77. Northouse LL, Williams AL, Given B, McCorkle R. Psychosocial care for family caregivers of patients with cancer. J Clin Oncol. 2012;30(11): $1227-1234$.

78. Northouse LL, Katapodi MC, Schafenacker AM, Weiss D. The impact of caregiving on the psychological well-being of family caregivers and cancer patients. Semin Oncol Nurs. 2012;28(4):236-245.

79. Mennin DS, Fresco DM. Emotion regulation therapy. In: Gross JJ, editor. Handbook of Emotion Regulation. 2nd ed. New York, NY: Guilford Press; 2013:469-490.

80. Applebaum AJ, Buda KL, O’Toole MS, Hoyt MA, Mennin DS. Adaptation of Emotion Regulation Therapy for Cancer Caregivers (ERT-C). Poster presented at: 14th Annual Conference of the American Psychosocial Oncology Society, February 15-18, 2017; Orlando, FL, USA.

81. Applebaum A. Emotion Regulation Therapy to address distress among cancer caregivers. Invited presentation for the T.J. Martell Annual Scientific Meeting 2018; Nashville, TN, USA.

82. Applebaum A, Son T, Bevans M, Hernandez M, DuHamel K. The unique experience of caregivers of outpatient hematopoetic stem cell transplant (HSCT) patients: lessons learned from the inpatient HSCT Literature. Poster presented at: 11th Annual Conference of the American Psychosocial Oncology Society, February 13-15, 2014; Tampa, FL, USA.

83. Dellmann-Jenkins M, Blankemeyer M. Emerging and young adulthood and caregiving. In: Shifren K, editor. How Caregiving Affects Development: Psychological Implications/Or Child, Adolescent, and Adult Caregivers. Washington, DC, USA: American Psychological Association; 2009:93-118.

84. Brody EM. Women in the Middle: Their Parent-Care Years. New York: Springer; 2004 
Psychology Research and Behavior Management is an international, peerreviewed, open access journal focusing on the science of psychology and its application in behavior management to develop improved outcomes in the clinical, educational, sports and business arenas. Specific topics covered in the journal include: Neuroscience, memory and decision making; Behavior
Submit your manuscript here: https://www.dovepress.com/psychology-research-and-behavior-management-journal modification and management; Clinical applications; Business and sports performance management; Social and developmental studies; Animal studies. The manuscript management system is completely online and includes a very quick and fair peer-review system, which is all easy to use. Visit http://www. dovepress.com/testimonials.php to read real quotes from published authors. 